\title{
SILICON NITRIDE BASED NON-VOLATILE MEMORY STRUCTURES WITH EMBEDDED Si OR Ge NANOCRYSTALS
}

\begin{abstract}
Memory structures with an embedded sheet of separated Si or Ge nanocrystals were prepared by low pressure chemical vapour deposition using a $\mathrm{Si}_{3} \mathrm{~N}_{4}$ control and $\mathrm{SiO}_{2}$ tunnel layers. It was obtained that a properly located layer of semiconductor nanocrystals can improve both the charging and retention behaviour of the MNOS structures simultaneously. Memory window width of above 6 V and retention time of 272 years was achieved for charging pulses of $\pm 15 \mathrm{~V}, 10 \mathrm{~ms}$.
\end{abstract}

\section{Introduction}

Information storage in non-volatile memories is based on changing the threshold voltage of memory field effect transistors (FETs) by appropriate voltage pulses. The actual mechanism is injection of charge by tunneling and its storage in a floating gate, or in traps in metal-nitride-oxide-semiconductor (MNOS) or silicon-oxidenitride-oxide-silicon (SONOS) devices located in the nitride layer close to the $\mathrm{SiO}_{2} / \mathrm{Si}_{3} \mathrm{~N}_{4}$ interface [1-8].

Nowadays memory arrays are based mainly on floating gate FETs. The reduction of dimensions is limited in these devices mainly due to reliability problems connected with defects in the thin oxide layer below the floating gate (tunnel oxide). The main problem is that through defects or weak points in tunnel oxide with reduced thickness the whole amount of stored charge carrying the information can be lost [1,6-8].

One of the possible solutions is to replace floating gate with separated semiconductor nanocrystals (NCs), which are electrically isolated. In this case the loss of information via local defects can be avoided [3-8].

Another possible way to avoid the above difficulties is the application of SONOS or MNOS devices. In these structures the charge holding the information is stored in the traps of nitride layer, which are electrically isolated by their nature. So, the effect of local defects in the tunnel oxide is reduced significantly $[4,7-9]$.

Our group realized that formation of semiconductor NCs in nitride based memory structures can enhance both the charging and retention behaviour due to making direct tunneling possible to NCs and creating deep energy states, respectively. So, our idea was to realize MNOS structures with $\mathrm{Si}$ or Ge NCs at the $\mathrm{Si}_{3} \mathrm{~N}_{4} / \mathrm{SiO}_{2}$ interface [8-10]. Although two earlier works were devoted to the study the effect of semiconductor NCs in SONOS structures [9, $11]$, to the best of our knowledge we are the only group studying this effect in MNOS structures.

\section{Experiment}

For tunnel layer a $\mathrm{SiO}_{2}$ layer was prepared after cleaning the wafers in $1 \mathrm{wt} \% \mathrm{HF}$. The $\mathrm{SiO}_{2}$ layer was prepared using a $\mathrm{HNO}_{3}$ treatment [12]; n-type Si wafers were immersed in $68 \mathrm{wt} \% \mathrm{HNO}_{3}$ at the boiling temperature $\left(121^{\circ} \mathrm{C}\right)$ for 60 minutes. This method yielded a $\mathrm{SiO}_{2}$ layer with a thickness of $2.5 \mathrm{~nm}$, as obtained by cross-sectional transmission electron microscopy [13].

The Si NC layer and the $\mathrm{Si}_{3} \mathrm{~N}_{4}$ control layer were deposited by LPCVD on n-type Si substrates at $830{ }^{\circ} \mathrm{C}$ at a pressure of $30 \mathrm{~Pa}$ using $\mathrm{SiH}_{2} \mathrm{Cl}_{2}$ and $\mathrm{NH}_{3}$. The $\mathrm{Si}_{3} \mathrm{~N}_{4}$ layers were grown at gas flow rates of $\mathrm{SiH}_{2} \mathrm{Cl}_{2}$ and $\mathrm{NH}_{3}$ of 21 and $90 \mathrm{sccm}$, respectively, while the $\mathrm{Si} \mathrm{NC}$ layer with a gas flow rate of $\mathrm{SiH}_{2} \mathrm{Cl}_{2}$ of $100 \mathrm{sccm}$. The duration of deposition for the Si NC layer was $30 \mathrm{~s}$ and $60 \mathrm{~s}$. Reference structures without $\mathrm{Si} \mathrm{NC}$ layer were also prepared. $\mathrm{Si}_{3} \mathrm{~N}_{4}$ control layer for structures with Si NCs was grown during $15 \mathrm{~min}$, which yielded a layer thickness of 37-40 nm, obtained by ellipsometry.

In the MNOS structures with embedded Ge NCs the effects of duration of $\mathrm{Ge} \mathrm{NC}$ deposition were studied as well ( $25 \mathrm{~s}$ and $50 \mathrm{~s}$ ). Ge nanocrystals were deposited by electron beam evaporation at $350{ }^{\circ} \mathrm{C}$ [14]. The thickness of the control $\mathrm{Si}_{3} \mathrm{~N}_{4}$ layer was about $35 \mathrm{~nm}$. Reference devices without any Ge nanocrystal layers were also prepared.

\footnotetext{
* Zs. J. Horvath ${ }^{1,2}$, P. Basa ${ }^{1}$, T. Jaszi ${ }^{1}$, A. E. Pap ${ }^{1}$, Gy. Molnar ${ }^{1}$, A. I. Kovalev ${ }^{3}$, D. L. Wainstein ${ }^{3}$, T. Gerlai ${ }^{1}$, P Turmezei ${ }^{2}$

${ }^{1}$ Hungarian Academy of Sciences, Research Institute for Technical Physics and Materials Science, Budapest, Hungary

${ }^{2}$ Obuda University, Kando Kalman Faculty of Electrical Engineering, Institute of Microelectronics and Technology, Budapest, Hungary

${ }^{3}$ Surface Phenomena Researches Group (SPRG), CNIICHERMET, Moscow, Russia

E-mail: horvzsj@mfa.kfki.hu, Horvath.Zsolt@kvk.obuda-uni.hu
} 
For electrical and memory measurements $\mathrm{Al}$ capacitors were formed with dimensions of $0.8 \mathrm{~mm}$ by $0.8 \mathrm{~mm}$ by evaporation. For backside ohmic contact also $\mathrm{Al}$ was evaporated after an appropriate chemical surface treatment [15].

The crystal structure of the layers was studied by X-ray photoelectron spectroscopy (XPS). Memory window and retention measurements were carried out on the capacitors. In this case the appropriate parameter for the characterisation of the memory effect and retention behaviour is the shift of flat-band voltage of capacitor. Memory window measurements were performed using voltage pulses with amplitude in range \pm 3 to $\pm 25 \mathrm{~V}$ and width in range $10 \mathrm{~ms}$ to $400 \mathrm{~ms}$. To enhance the development of the inversion layer, and so to avoid high voltage drop on the deep depletion layer during negative voltage pulses, the structures were illuminated with white light during memory window measurements. Retention measurements were performed in dark.

\section{Results and Discussion}

XPS results obtained on the MNOS structures after removing the upper part of the control silicon nitride layer clearly indicate the presence of NCs at the oxide/nitride interface, as it is presented in Fig. 1 for the structures with Si NC deposition duration of $30 \mathrm{~s}$ and $60 \mathrm{~s}$. The Si NC peak is much more pronounced for a deposition duration of $60 \mathrm{~s}$, than for $30 \mathrm{~s}$, as it was expected.

a)

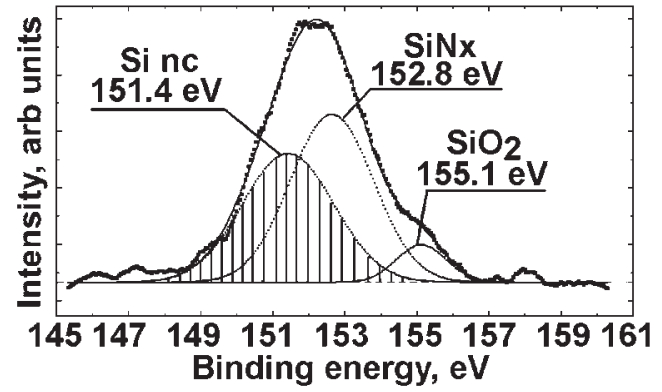

b)

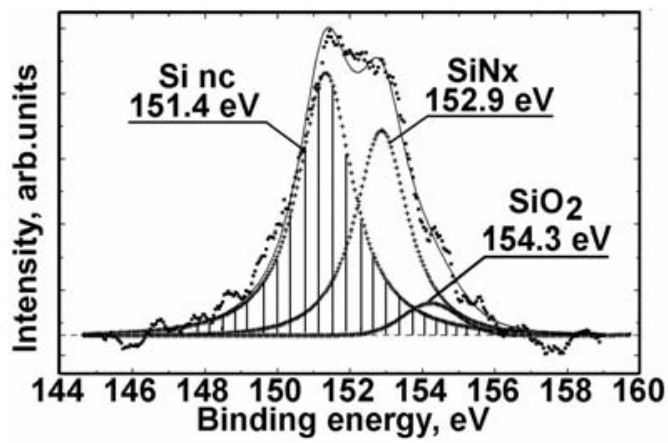

Fig. 1. Si 2s photoelectron spectrum of MNOS structures with Si nanocrystal deposition duration of $30 \mathrm{~s}($ a) and $60 \mathrm{~s}$

(b) after Ar ion etching at depth of $38 \mathrm{~nm}$.
The results of memory window measurements as a function of charging pulse amplitude with pulse width of 10 and $150 \mathrm{~ms}$ are presented in Fig. 2 for structures with Si nanocrystal deposition duration of $60 \mathrm{~s}$. For longer charging pulses a wider memory window was obtained. The effect of Si NC deposition on the memory window is demonstrated in Fig. 3, which presents the memory window width for structures with Si nanocrystal deposition duration of 30 $\mathrm{s}$ and $60 \mathrm{~s}$, and without middle NC layer deposition (indicated as $0 \mathrm{~s}$ duration), as a function of charging pulse amplitude. The structures with Si NCs exhibited a wider memory window for the whole studied voltage range than the reference structure.

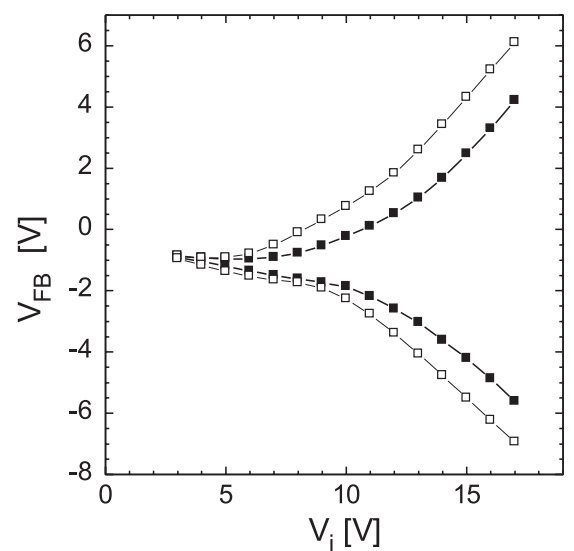

Fig. 2. The position of a memory window as a function of writing/erasing pulse amplitude with the pulse width of $10 \mathrm{~ms}$ (filled dots) and $150 \mathrm{~ms}$ (open dots) for the studied MNOS structures with Si nanocrystal deposition duration of $60 \mathrm{~s}$. The upper curves are obtained for positive, the lower curves for negative voltage pulses.

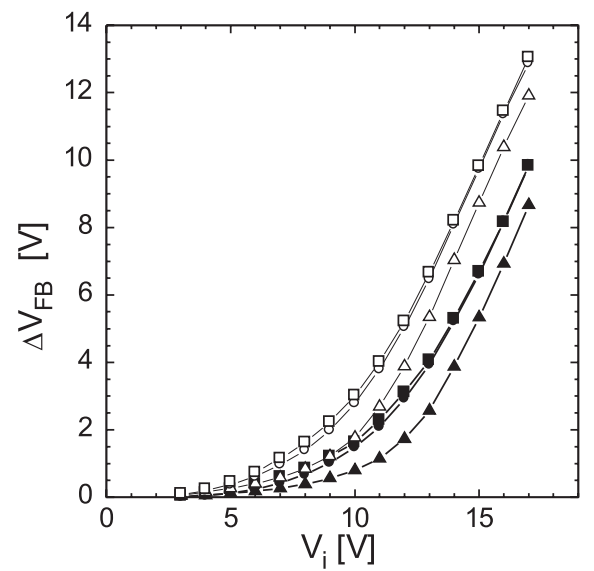

Fig. 3. The memory window width as a function of writing/erasing pulse amplitude with the pulse width of $10 \mathrm{~ms}$ (filled dots) and $150 \mathrm{~ms}$ (open dots) for the studied MNOS structures with Si nanocrystal deposition duration of $0 \mathrm{~s}$ (triangles), $30 \mathrm{~s}$ (circles), and $60 \mathrm{~s}$ (squares).

Retention behaviour is determined on the basis of flat-band voltage shift as a function of time after the application of a charg- 
ing pulse. This shift of flat-band voltage is due to the loss of charge holding the information, through the tunnel and/or control layer. The shift exhibits logarithmic dependence on the time. So, plotting flat-band voltage as a function of the logarithm of time, a linear relation is obtained. The retention time (the time necessary to the lost of information) or the width of memory window after a certain time can be extrapolated from this linear relation fitted to the experimental data points [10]. Results concerning the retention behaviour of the studied structures with Si NCs are presented in Table 1. It is seen that the presence of $\mathrm{Si}$ NCs decreased the retention time, but for the samples with $\mathrm{NC}$ deposition of $30 \mathrm{~s}$ the memory window width after 10 years is still detectable. The extrapolation of flat-band voltage shift yielded a retention time of 41 years for these samples. It is even much higher than the standard requirement of 10 years.

The initial and extrapolated from the retention

Tab. 1. measurements for 1 and 10 years memory window widths for the studied structures. The charging pulse amplitude was $\pm 15 \mathrm{~V}$, the pulse width $10 \mathrm{~ms}$

\begin{tabular}{|c|c|c|c|c|c|}
\hline $\begin{array}{c}\text { Nano- } \\
\text { crystal }\end{array}$ & $\begin{array}{c}\text { Nano- } \\
\text { crystal } \\
\text { deposition } \\
\text { duration } \\
(\mathrm{s})\end{array}$ & $\begin{array}{c}\text { Initial } \\
\text { memory } \\
\text { window } \\
\text { width (V) }\end{array}$ & $\begin{array}{c}\text { Extrapolated } \\
\text { memory } \\
\text { window after } \\
\text { 1 year (V) }\end{array}$ & $\begin{array}{c}\text { Extrapolated } \\
\text { memory } \\
\text { window } \\
\text { after 10 } \\
\text { years (V) }\end{array}$ & $\begin{array}{c}\text { Retention } \\
\text { time } \\
\text { (years) }\end{array}$ \\
\hline $\mathrm{Si}$ & 0 & 5.34 & 0.87 & 0.46 & 128 \\
\hline $\mathrm{Si}$ & 30 & 6.61 & 0.85 & 0.32 & 41.2 \\
\hline $\mathrm{Si}$ & 60 & 6.68 & 0.47 & 0 & 7.37 \\
\hline $\mathrm{Ge}$ & 0 & 5.81 & 0.72 & 0.22 & 27.0 \\
\hline $\mathrm{Ge}$ & 25 & 6.31 & 1.14 & 0.67 & 272 \\
\hline $\mathrm{Ge}$ & 50 & 6.12 & 0.25 & 0 & 2.64 \\
\hline
\end{tabular}

The results of memory window measurements of MNOS structures with Ge nanocrystals as a function of writing/erasing pulse amplitude with pulse width of $100 \mathrm{~ms}$ are presented in Fig. 4. The memory window is somewhat wider for memory structures with NCs than in the reference sample. However, while in the structures with Si NCs a longer deposition duration of NCs yielded a wider memory window, in the structures with Ge NCs the memory window is wider for a shorter deposition time.

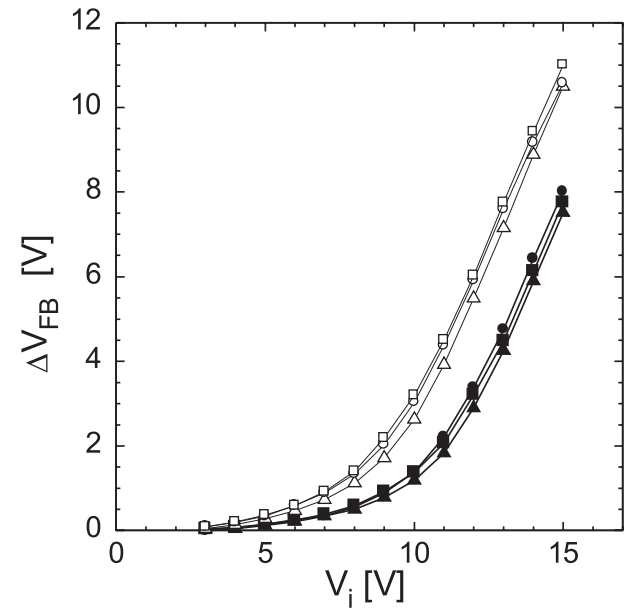

Fig. 4. The memory window width as a function of writing/erasing pulse amplitude with the pulse width of $10 \mathrm{~ms}$ (filled dots) and $150 \mathrm{~ms}$ (open dots) for the studied MNOS structures with Ge nanocrystal deposition duration of $0 \mathrm{~s}$ (triangles), $25 \mathrm{~s}$ (circles), and $50 \mathrm{~s}$ (squares).

The retention behaviour of the structures with Ge NCs is also summarized in Table 1. The best retention time of 272 years was obtained for $\mathrm{Ge} \mathrm{NC}$ deposition duration of $50 \mathrm{~s}$. It is very important that both injection and retention performances of samples with deposition duration of $50 \mathrm{~s}$ are better than those for reference samples without NCs. This demonstrates that a sheet of semiconductor NCs can improve both the injection and retention behaviour of silicon nitride based memory devices simultaneously $[7,8]$.

\section{Summary}

MNOS structures with embedded Si or Ge nanocrystals were prepared by LPCVD and studied by memory window and retention measurements. Both the memory window and retention depended on the presence and deposition duration of nanocrystals. The presence of nanocrystals increased the memory window width, and enhanced in some cases the retention behaviour as well. The results demonstrate that a sheet of semiconductor nanocrystals can improve both the injection and retention behaviour of silicon nitride based memory devices.

\section{References}

[1] PARAT, K. K.: Flash Memory Technology - Recent Advances and Future Outlook, in Physics of Semiconductor Devices, (Eds. K. N. Bath and A. DasGupta), Narosha Publishing House, New Delhi, 2004, pp.433-438.

[2] NORMAND, P., KAPETANAKIS, E., DIMITRAKIS, P., SKARLATOS, D., BELTSIOS, K., TSOUKALAS, D., BONAFOS, C., BEN ASSAYAG, G., CHERKASHIN, N., CLAVERIE, A., BERG, J. A. VAN DEN, SONCINI, V., AGARWAL, A., AMEEN, M., PEREGO, M., FANCIULLI, M.: Nanocrystals manufacturing by ultra-low-energy ion-beam synthesis for non-volatile memory applications, Nucl. Instr. and Meth. B, Vol. 216, 2004, pp. 228-238, and references therein.

[3] DIMITRAKIS, P., KAPETANAKIS, E., TSOUKALAS, D., SKARLATOS, D., BONAFOS, C., ASSAYAG, G. BEN, CLAVERIE, A., PEREGO, M., FANCIULli, M., SONCINI, V., SOTGIU, R., AGARWAL, A., AMEEN, M., SOHL, CH., NORMAND, P.: 
Silicon nanocrystal memory devices obtained by ultra-low-energy ion-beam synthesis, Solid-State Electron., Vol.48, 9/2004, pp. 1511-1517.

[4] DE SAlVO, B., GERARDI, C., SCHAiJK, R. VAN, LOMBARDO, S. A., CORSO, D., PlANTAMURA, C., SERAFINO, S., AMMENDOLA, G., DUUREN, M. VAN, GOARIN, P., MEI, W. Y., JEUGD, K. VAN DER, BARON, T., GÉLY, M., MUR, P., DELEONIBUS, S.: Performance and Reliability Features of Advanced Nonvolatile Memories Based on Discrete Traps (Silicon Nanocrystals, SONOS), IEEE Trans. Dev. Mater. Reliability, Vol.4, 3/2004, 377-389, and references therein.

[5] PODOR, B, HORVATH, ZS. J., BASA, P.(Eds.): Semiconductor Nanocrystals; Proc. First Int. Workshop on Semiconductor Nanocrystals SEMINANO2005, Sept. 10-12, 2005, Budapest, Hungary Vols. 1 and 2; http://www.mfa.kfki.hu/conferences/seminano2005/

[6] HORVATH, ZS. J.: Semiconductor Nanocrystals in Dielectrics: Optoelectronic and Memory Applications of Related Silicon Based MIS Devices, Current Appl. Phys., Vol. 6, 2/2006, pp.145-148, and references therein.

[7] HORVATH, ZS. J., BASA, P.: Nanocrystal Non-volatile Memory Devices, Mater. Sci. Forum, Vol. 609, 2009, pp. 1-9, and references therein.

[8] HORVATH, ZS. J., BASA, P.: Chapter 5: Nanocrystal memory structures, in: Nanocrystals and Quantum Dots of Group IV Semiconductors, (Eds. T. V. Torchinskaya, Yu. V. Vorobiev), American Scientific Publishers, in press, and references therein.

[9] RAO, R. A., STEIMLE, R. F., SADD, M., SWIFT, C. T., HRADSKY, B., STRAUB, S., MERCHANT, T., STOKER, M., ANDERSON, S. G. H., ROSSOW, M., YATER, J., ACRED, B., HARBER, K., PRINZ, E. J., WHITE JR., B. E., MURALIDHAR, R.: Silicon nanocrystal based memory devices for NVM and DRAM applications, Solid-State Electron., Vol. 48, 2004, pp.1463-1473.

[10] HORVATH, ZS. J., BASA, P., JASZI, T., PAP, A. E., DOBOS, L., PACZ, B., TOTH, L., SZOLlOSI, P., NAGY, K.: Electrical and Memory Properties of $\mathrm{Si}_{3} \mathrm{~N}_{4}$ MIS Structures with Embedded Si Nanocrystals, J. Nanosci. Nanotechnol., Vol. 8, 2/2008, pp.812-817.

[11] AMMENDOLA, G., ANCARANI, V., TRIOLO, V., BILECI, M., CORSO, D., CRUPI, I., PERNIOLA, L., GERARDI, C., LOMBARDO, S., DESALVO, B.: Nanocrystal memories for FLASH device applications", Solid-State Electron., Vol. 48, 2004, pp. 14831488

[12] KOBAYASHI, H., ASHUA, MAIDA, O., TAKAHASHI, M., IWASA, H.: Nitric Acid Oxidation of Si to Form Ultrathin Silicon Dioxide Layers with a Low Leakage Current Density, J. Appl. Phys., Vol. 94, 6/2003, pp. 7328-7236.

[13] DOBOS, L., PECZ, B., TOTH, L.: unpublished.

[14] BASA, P., MOLNAR, GY., DOBOS, L., PECZ, B., TOTH, L., TOTH, A. L., KOOS, A. A., DOZSA, L., NEMCSICS, A., HORVATH, ZS. J.: Formation of Ge Nanocrystals in $\mathrm{SiO}_{2}$ by Electron Beam Evaporation, J. Nanosci. Nanotechnol., Vol. 8, 2/2008, pp. 818-822.

[15] HORVATH, ZS. J., ADAM, M., SZABO, I., SERENYI, M., TUYEN, VO VAN.: Modification of Al/Si Interface and Schottky Barrier Height with Chemical Treatment, Appl. Surf. Sci., Vol. 190, 5/2002, pp. 441-444. 